\title{
Elicitation Questions in English and Persian Written Texts: A Comparative Study
}

\author{
Janin Jafari ${ }^{1, *}$ \\ ${ }^{1}$ School of Languages, Cultures, and Linguistics, Monash University, Melbourne, Australia \\ *Correspondence: 950 High St. Road, Glen Waverley, Victoria 3150, Australia \\ Tel: 61-415-503-891_E-mail: janin.jafari@monash.edu
}

Received: May 6, 2013

doi:10.5430/wjel.v3n2p34
Accepted: June 3, $2013 \quad$ Online Published: June 17, 2013

URL: http://dx.doi.org/10.5430/wjel.v3n2p34

\begin{abstract}
This paper is devoted to a comparative study of 'Elicitation Questions' in English and Persian written texts. It examines the feasibility of Tsui's (1995) model of conversational structure, particularly with respect to different subcategories of 'Elicitation Questions' which are basically function-based. To this end, six best-selling story books in English and Persian were chosen. The data gathered were first, subjected to descriptive statistics and then to inferential statistics by using Chi-square test. The findings led to the following conclusions: (1)Tsui's characterization of the utterance which occurs in the initiating move and elicits an obligatory verbal response as an 'Elicitation Questions' regardless of its syntactic form is applicable to the conversational structure of English and Persian story books; (2)Tsui's classification of 'Elicitation Questions' into five subcategories which is basically function-based is proper and workable in English and Persian texts; (3) 'Elicitation Questions' in both English and Persian texts were mostly asked for getting Information and Clarification. In English texts, they were asked for Repetition and then Agreement, while in Persian texts these tendencies were reverse. Regarding asking for Commitment and Repetition, they were the least frequent types in English and Persian respectively; (4) the elicited responses are also in accordance with Tsui's classification of responding moves with reference to the third element of conversation; in most cases no follow-up move was realized.
\end{abstract}

Keywords: elicitation questions; conversational structure; elicitation classifications

\section{Introduction}

Main sentences according to their conventional use in natural languages are divided into declarative sentences usually used to report facts; interrogative sentences primarily used to ask questions; and imperatives which are used to make requests. Although types of sentences can vary from language to language it appears that the three basic sentence types: declarative, interrogative and imperative are universal. These sentence types can realize twenty-one discourse acts and three of them which occur in all forms of spoken discourse are: elicitation, directive and informative. Quirk, Greenbaum, Leech, and Svartivk, (1985) state that the use of these syntactic types correlates largely with different discourse functions. Statements correlate mostly with the act of conveying information; questions correlate mostly with the act of seeking information on a specific point; directive correlate commonly with the act of directing someone how to do something and "exclamations are primarily used for expressing the extent to which the speaker is impressed by something"(p. 804).

Recently, however, the nature of this correlation has been called into questions. As Lyons (1981, p. 141) points out “... statements, questions, and commands are only a few of the many functionally distinguishable speech acts which are systematically inter-related in various ways." Among the sentence types, interrogatives either expect the addressee to give a positive or negative answer or to provide the addressee with new information. In what follows a number of classifications will be reviewed to indicate how a variety of utterances have been identified as questions on the basis of different viewpoints.

Quirk, et al. (1985) consider question as a semantic class mainly used to seek information on a specific point. They divide questions into three major classes according to the type of answers such sentences expect: 
1) Yes/No questions that expect affirmation or negation, as in "Have you opened the window?"

2) WH-questions/information questions that typically expect an answer from an open range of answers, as in "Where is your home?"

3) Alternative questions that typically expect an answer based on one of two or more options presented in the question, as in "Would you like to WATCH TV or READ a book?"

They further classify yes/no questions into neutral and conducive questions. Neutral questions have no bias for eliciting yes or no answers. However, conducive questions contain some elements which make them biased towards either a positive or a negative answer. In addition, tag questions and declarative questions have also been classified under yes/no questions on the basis of responses they prospect.

Although Quirk, et al. (1985) claim that their classification of question is made according to the response expected, Tsui (1995) shows that in their actual characterization of different classes of questions, the precedence is given to syntactic form rather than the expected responses. In other words, they pay more attention to the form of the responses than the function or the communicative choice realized by the responses.

Lyons (1981) defines 'question' as an utterance with a particular illocutionary force. According to Falk (1978, p. 264), illocutionary force refers to “... the speaker's communicative intention in producing an utterance;" she adds, "Types of illocutionary force include assertions, requests, requests for action (imperatives), and requests for information (questions)." Lyons (1981) makes a distinction between questions and statements as illocutionary acts. He explains that the former is characterized by a feature of doubt and that it is felicitous if the speaker does not know the answer to the question. Moreover, he maintains that the association of a response with a question is conventional and independent of the illocutionary force of the question.

Tsui (1995) claims that Lyon's characterization of questions is not consistent for two reasons. First, if the expectation of answer is independent of the illocutionary force of a question, then there should be no distinction between the following two questions:

Is the door locked?

The door is locked, isn't it?

However, it is clear that Lyons (1981) makes a distinction between the two questions by referring to the type of answers they prospect. Second, since Lyon's characterization of questions does not contain the feature of doubt (because the speaker already knows the answer), it is difficult to see how rhetorical questions can be considered as a kind of question.

It seems that Lyons took into account both syntactic form and discourse function. Therefore, inconsistent criteria are used in the identification and classification of 'questions'. So the category of question lies equally between a syntactic category and a discourse category. Katz and Postal, Gordon and Lakoff, Katz, Labov, and Fenshel (as cited in Tsui, 1995) consider questions as requests for information and propose that the logical form of questions should be "I request you tell me" rather than "I ask you". Katz (as cited in Tsui, 1995, p. 79) characterizes questions as “... requests which have the purpose of eliciting information." Huddleston and Pullum (2002, pp. 865-6) discuss kinds of question in detail based on recent grammatical and pragmatic insights.

Katz and Postal (1964, p. 85) propose that an important fact about question is that "Semantically, they are somewhat like imperatives in that questions are requests of specific kind." They conclude that "Unlike imperatives, which, in general, request some form of nonlinguistic behavior or action, questions are concerned primarily with linguistic responses" (p. 86). Questions have also been characterized as a kind of directive because a directive is an instruction to do something and questions are instructions to make a verbal performance.

While this kind of characterization is superior to that of Lyons and Quirk, et al. in that it does not confuse form and function, it is not without problems. In other words, the discourse function of 'question' is different from that of 'request'. In this regard, Tsui (1995) criticizes this kind of characterization and asserts that questions and requests prospect two completely different answers. Questions prospect an obligatory verbal response or a non-verbal surrogate and the interaction between the speaker and the addressee is completed at the verbal level; whereas, requests expect an obligatory non-verbal response and sometimes accompany a verbal response which is completed at the non-verbal level.

Tsui (1995) adopted the term 'Elicitation' from Sinclair and Coulthard (1992) who for the first time used it to refer to the classroom utterances which elicit a verbal response. In the description of conversations, she borrows the terms: act, move and exchange from Sinclair and Coulthard's descriptive framework (Coulthard, 1992). She also maintains 
that a three-part exchange, i.e. initiation, response and follow-up, is more powerful as a description of the basis unit of conversational organization than an adjacency. Based on the structural location criterion, Tsui (1991) establishes three primary classes of acts: a) initiating acts (initiations) which occur at the head of the initiating move, b) responding acts (responses) which occur at the head of the responding move and c) follow-up acts (follow-ups) which occur at the head of the follow-up move. Then she distinguishes four subclasses of initiating acts as: directives, requestives, informatives and elicitations. Elicitations are those verbal responses that supply the missing information indicated in the initiating move.

Accordingly, Tsui (1995, p. 81) describes that the term 'Elicitation' is used as "A discourse category to describe any utterance, both inside and outside the classroom which functions to elicit an obligatory verbal or its non-verbal surrogate." She further classifies elicitations into six subcategories in terms of different responses they expect. The six subcategories appear in the following:

\section{Elicit: Inform}

The first subcategory refers to Elicitations which function to elicit a piece of missing information. This subcategory may be realized in the form of yes/no questions, wh-questions, alternative questions or indirect questions.

\section{Elicit: Confirm}

The second subcategory refers to Elicitations which invite the addressee to confirm what the speaker assumes to be true. This subcategory may be realized in the form of tag questions, negative and positive polarity interrogatives.

\section{Elicit: Agree}

The third subcategory consists of Elicitations which invite the addressee to agree with the speaker's assumption that the expressed proposition is self-evidently true. This kind of Elicitation is often used to start a conversation, especially between strangers, to make positive and negative polar interrogatives.

\section{Elicit: Commit}

The fourth subcategory elicits a verbal response and some sort of commitment on the part of addressee. This subcategory may be realized by yes/no questions or wh-interrogatives. The interrogatives in this subcategory are similar to requests in the sense that if responded to positively, they will involve some sort of commitment to further action. However, they differ from requests because they obligatorily elicit a verbal response while it is optional in requests.

\section{Elicit: Repeat and 6. Elicit: Clarify}

The fifth and sixth subcategories Elicit: Repeat and Elicit: Clarify, prospect a repetition and clarification of a preceding utterance(s). Elicit: Repeat may be realized by wh-interrogatives such as "Who/When/Where/What did you say?", or words such as "Sorry?", "Pardon?" or "Huh?". Elicit: Clarify can be realized by wh-interrogatives such as "What do you mean?", "Which room?" or "What?"

\section{Response to Elicitation}

As Tsui (1995) points out, responses have been given little attention in the speech act literature. This is because of the characterization of illocutionary acts which is often carried out by making a semantic analysis of performative verbs rather than by considering the function of utterances in discourse. Response acts, therefore, are neglected because they do not have corresponding performative verbs. Knowing both the illocutionary intent and the pragmatic presuppositions of the initiation are important criteria for identifying the responding move. If the responding move meets the presuppositions and the illocutionary intent of the preceding utterance, then the move can be characterized as a responding move; otherwise, it will challenge the preceding utterance and will be characterized as a challenging move.

Fully-fitting responding acts which are preferred fulfill the illocutionary intent and imply the pragmatic presuppositions of the initiating move and are labeled positive responding acts. The utterances which do not fulfill the illocutionary intent and challenge the pragmatic presuppositions of the initiating act can be categorized as negative responding acts which are dispreferred. Temporizations are other kinds of dispreferred responding acts which do not fulfill the illocutionary intent of the initiating move, but they do not challenge its pragmatic presuppositions, which also postpone the decision-making.

Although all challenges are dispreferred and face-threatening, some of them are more face-threatening than others. Tsui (1995, p. 166) points out that "Challenging the presupposition that one is able to provide the requested 
information is less face-threatening than challenging the presupposition that one is willing to provide the requested information." This is why participants who are unwilling to provide information usually make use of declaration of ignorance, such as "I don't know", and also use fillers, hesitation or evasive answers. Therefore, only fully-fitting answers which fulfill the illocutionary intent of the speaker serve as positive answers to Elicitations. However, elicit: commit is an exception which commits the addressee to a future verbal or non-verbal action, like requestives, then all three subclasses of responding acts can be realized and there is no challenging move.

\section{Follow-up Acts}

Follow-up acts generally aim to acknowledge the outcome of an exchange. They are subcategorized as: endorsement, concession and acknowledgment. These three subclasses are determined on the basis of prospective classification. Follow-up acts which endorse the positive outcome of the interaction are identified as endorsement and realized by items such as 'wonderful', 'good', 'splendid', etc. For example, in an Elicit: Inform, if the provided information is considered as a service rendered, an appreciation for the service rendered or a comment on the information can show an endorsement.

A follow-up act which has the function of accepting a negative outcome of the intention is labeled a concession. Since negative responses do not fulfill the illocutionary intent of the preceding initiation, they are face-threatening effect of the negative response. The other subclass of follow-up act is a minimal acknowledgment that the response has been heard, understood or accepted and the interaction has been felicitous. This type of follow-up act can be realized by items such as 'okay', 'right', 'alright', 'yeah', 'oh I see' or a repetition of the preceding response in low key. Acknowledgments may follow all three subclasses of responding acts.

\section{Purpose of the Study}

This study was carried out to find answers to the following questions:

1) Is Tsui's characterization of utterance applicable to the conversational structure of English and Persian story books?

2) Is Tsui's classification of 'Elicitation Questions' workable in English and Persian story books?

3) Which one of Tsui's Elicitation Questions' subcategories is the most frequently used in English and Persian story books?

4) Are the elicited responses in accordance with Tsui's classification of responding moves in English and Persian story books?

\section{Method}

The corpus of this study consists of three English and three Persian story books. The three English story books are:

1) The Glass Menagerie (Williams, 1944)

2) The Time of Your Life (Saroyan, 1939)

3) Trifles (Glaspell, 1948)

And the three Persian story books are:

1) Arusiye-Khubaan (Makhmalbaf, 1987)

2) Rouzane-ye-Aabi (Radi, 1961)

3) Vaay Bar Maqlub (Saedi, 1977)

In fact, a systematic method is used to select the data for the study. Three English and three Persian story books, which are written by famous contemporary writers and are best-sellers in the recent decades, were selected randomly. The most important reason for choosing these story books lies in the fact that their language is spontaneous and close to the natural everyday conversations. After a systematic search for identifying five sub-categories of 'Elicitation Questions', 361 English and 337 Persian dyads were analyzed. It is worth noting that Persian instances were also transcribed and subsequently transliterated for data analysis. 


\section{Analysis of the Data}

First, 'Elicitation Questions' both in English and Persian story books were detected and extracted. It is noticeable to mention that Elicit: Confirm is not included in the study because the discourse function in it depends on the intonation employed by the speakers. Second, the data were analyzed in terms of the conversational structure model proposed by Tsui (1995) as in the following:

1. Elicit: Inform

The Elicitations which invite the addressee to supply a piece of information.

2. Elicit: Agree

The Elicitations which invite the addressee to agree with the speaker's assumption that the expressed proposition is self-evidently true.

\section{Elicit: Commit}

The Elicitations which elicit more than just a verbal response from the addressee. It also elicits commitment of some kind.

\section{Elicit: Repeat and 5. Elicit: Clarify}

The Elicitations which prospect a repetition and clarification of a preceding utterance(s).

The following examples with their analyses are given for further illustration:

Elicit: Inform

1.

I. 1 A: baa xadije che kaar mikon-i?

With khadije what work do + present, $2^{\text {nd }}$ per., sing. (you)

What do you want to do with Khadije?

R. 1 B: miferest-am-ash karbaas mahalleh.

Send I her karbaas district

Am: + present, $1^{\text {st }}$ per., sing. (I) ash: $3^{\text {rd }}$ per., sing., (her)

I will send her to Karbaas district.

(Saedi, 1977, p. 58)

2.

I. 1 A: Where are you going?

R.1 B: I'm going to the movies.

(William, 1944, p. 994)

3.

I. 1 A: Haven't you ever liked some boy?

R.1 B: Yes. I liked one once. I came across his picture a while ago.

(William, 1944, p. 996)

4.

I. 1 A: Is there a moon this evening?

R.1 B: It's rising over Garfinkl's Delicatessen.

(William, 1944, p. 1002)

Initiating moves (I. 1) in examples (1) and (2) are instances of information seeking questions. Therefore, in both cases, the addressee provides the speaker with the requested information. The responses are both positive and preferred because both meet the illocutionary intent of the speakers. In these interactions no follow-up has been realized. It may be concluded that follow-up acts occur more in spoken forms than in written forms because in a face-to-face interaction the follow-up moves may be realized non-verbally. 
In (3), I. 1 is what Quirk, et al. (1985) refer to as "negative polarity interrogative" which prospects a negative answer. Nevertheless, it is apparent that A's utterance (I. 1) is not negatively oriented and its discourse function is to elicit information. In this case, the responding move is positive and fulfills the presupposition underlying the preceding utterance. The follow-up act is also absent. This may be due to the fact that since A who seeks information is in a higher position, then the follow-up act may be realized non-verbally.

In (4), I. 1 is an example of "neutral polarity yes/no question" which implies that the speaker has no assumption as to whether the answer is 'yes' or 'no'. Here the speaker does not have any assumption to arouse confirmation or disconfirmation, but rather the speaker seeks information. In other words, this information seeking question does not necessarily prospect either a 'yes' or 'no' answer. The response to A's utterance (I. 1) fully fulfills the speaker's illocutionary intent and is a positive responding act. In this case no follow-up act is present. The reason can be due to the fact that the participants know each other well.

Elicit: Agree

1.

I. 1 A: sedaa-ye paa mishna-vi?

Sound of foot hear + present, $2^{\text {nd }}$ per., sing. (you)

There is a footstep. Do you hear?

R.1 B: ?aare mardaaneh ?ast.

Yes. Manly is

Yes. Of a man.

(Radi, 1961, p. 58)

2.

I. 1 A: Is it broken?

R.1 B: Now it is just like the other horses.

(William, 1944, p. 1014)

3.

I. 1 A: Did he seem pleased?

R.1 B: Yeah

(Saroyan, 1939, p. 694)

4.

I. 1 A: Is that you and Mr. O'Conner?

R.1 B: Yes, Mother.

(William, 1944, p. 1007)

The initiations in all these examples are 'neutral polarity yes/no questions' uttered with a question intonation which invite the addressees to agree with the speakers' assumption that the expressed propositions are self-evidently true. In this part the context of situation plays an important role in order to disambiguate the discourse function of the utterance. The absence of the follow-up acts may be because the utterances are taken from written forms rather than spoken forms.

Elicit: Commit

1.

I. 1 A: xaanoom chaa?i dam begozaar-am

Madam tea brew put + present, $1^{\text {st }}$ per., sing. (I)

Shall I brew the tea, madam?

R.1 B: chaa?iyee laahijan ?ast. kam ber-iz por zur

Tea of Lahijan is little pour strong

-iz: + present, $2^{\text {nd }}$ per., sing. (you) 
It is Lahijan tea, soo use little, and do

nabaashad baraaye qalb mozer ?ast.

not be for heart harmful is

not make strong tea. It is harmful for the heart.

(Radi, 1961, p. 56)

2.

I. 1 A: Mr. Nick can I play the piano again?

R.1 B: Sure. Practice all you like until I tell you to stop.

(Saroyan, 1939, p. 685)

3.

I. 1 A: Where'll I take them?

R.1 B: Given them to some kid. No, take them up to Kitty.

(Saroyan, 1939, p. 685)

I. 1 in both (1) and (2) is a neutral polarity yes/no question used to not only elicit a verbal response but also get the addressee to commit himself to do something. In this kind of Elicitation the speaker clarifies his/her intent by identifying the kind of commitment he/she demands on the part of the addressee.

In (3), I. 1 is another instance of Elicit: Commit realized by a wh-interrogative which invites the addressee not only to supply the missing information signaled by 'where', but also to commit to a specific place of taking toys. The follow-up acts in all interactions are absent. This may be because of the mentioned reasons.

Elicit: Repeat

1.

I. 1 A: goft-id saa?at chand ?sat?

tell you hour what is tell: + present, $2^{\text {nd }}$ per., sing. (you)

what time did you tell it is?

R.1 B: dar hodud-e se

In around of three

around three.

(Radi, 1961, p. 71)

2.

I. $1 \mathrm{~A}$ : Give me a pillow.

I. 2 B: What?

R.2 A: A pillow.

F. 1 B: Oh!

(William, 1944, p. 1010)

3.

I. 1 A: What have you done since high school?

I. 2 B: Huh?

R.2 A: I said what have you done since high school, Laura?

R.1 B: Nothing much.

(William, 1944, p. 1012)

The second initiating move (I.2) in both (1) and (2) is a wh-interrogative asking for a repetition of part of A's preceding utterance. All responding moves are positive and fulfill the presuppositions underlying the preceding utterances. However, in the first and the third interactions the follow-up acts are not observed. This may be due to the 
fact that the interlocutors know each other well, or it may be realized non-verbally. In (2), the follow-up act is realized by acknowledging receipt of information.

Elicit: Clarify

1.

I. 1 A: xod-am mi?aar-am-ash. ?az kodum var ber-am?

myself I bring from which direction take I

am: + present, $1^{\text {st }}$ per., sing. (I) ash: + present, $3^{\text {rd }}$ per., sing. (her)

I will bring her myself. Which direction shall we take?

R. 1 B: ?az jelow bepich be raast.

from straight turn to right

Go straight, then turn right.

(Makhmalbaf, 1987, p. 52)

2.

I. 1 A: Mother, you mustn't expect too much of Laura.

I. 2 B: What do you mean?

R.2 A: Laura seems all those things to you and me because she's ours and we love her.

(William, 1944, p. 1004)

3.

I. $1 \mathrm{~A}$ : What class was that?

R.1 B: It was singing-chorus.

F. 1 A: Aw.

(William, 1944, p. 1011)

I. 1 A: Who, for instance?

R.1 B: Me.

(Saroyan, 1939, p. 674)

I.2 in both (1) and (2) and also I.1 in (3) and (4) is a wh-interrogative used to ask for clarification of the preceding utterance. All elicitations are followed by positive responding acts. However, only the third interaction includes a follow-up act in A's utterance, which is in form of a minimal acknowledgment.

\section{Procedures}

The statistical procedures utilized were first, obtaining the frequency of each subcategory in the two languages; second, calculating the percentage of these Elicitations in both English and Persian texts; and third, running Chi-square tests to see if there were significant differences between the subcategories of a language and also among the two languages.

\section{Results and Discussion}

The questions obtained from the data analysis are presented in five subcategories of 'Elicitation Questions'- i.e., Information, Agreement, Commitment, Repetition and Clarification. The frequencies and percentages are given in the following table: 
Table 1: The Frequency of Different Types of 'Elicitation Questions' in English and Persian Texts

\begin{tabular}{lcccc}
\hline Elicitation Question Types & \multicolumn{2}{c}{ Frequencies } & \multicolumn{2}{c}{ Percentages } \\
& English & Persian & English & Persian \\
\hline Elicit: Inform & 219 & 214 & 66.66 & 63.50 \\
Elicit: Clarify & 99 & 83 & 27.42 & 24.63 \\
Elicit: Repeat & 21 & 5 & 5.82 & 1.49 \\
Elicit: Agree & 14 & 27 & 3.88 & 8.01 \\
Elicit: Commit & 8 & 8 & 2.22 & 2.37 \\
Total & $\mathbf{3 6 1}$ & $\mathbf{3 7 7}$ & $\mathbf{1 0 0}$ & $\mathbf{1 0 0}$ \\
\hline
\end{tabular}

Table 1 illustrates that questions which seek information and clarification were the most frequent types of Elicitation Question in both English and Persian texts. The Elicit: Repeat constituted 5.82 percent of this type of question in Persian texts. That is, the tendency of the English texts in the use of Elicit: Repeat was nearly four times as many as the Persian texts. This tendency was reverse in the case of Elicit: Agree. The English texts used 14 instances (3.88\%) of this type of question which was nearly twice less than that of the Persian texts. In the Elicit: Commit, however, both the English and Persian texts indicated nearly the same tendency in the use of Elicit: Commit. The English texts used 8 instances (2.22\%) compared with 8 instances in Persian texts $(2.37 \%)$.

The Chi-square test is applied to tap the significance of these differences. They are reported in the following tables:

Table 2: Different Types of 'Elicitation Questions' in English Texts

\begin{tabular}{cccccc}
\hline $\begin{array}{c}\text { Types of Questions } \\
\text { Language }\end{array}$ & Inform & Clarity & Repeat & Commit & Agree \\
\hline $\begin{array}{c}\text { English } \\
\mathbf{X}^{\mathbf{2}} \mathbf{4 4 8 . 7 ^ { * }}\end{array}$ & $60.66 \%$ & $27.42 \%$ & $5.82 \%$ & $3.88 \%$ & $2.22 \%$ \\
\hline
\end{tabular}

$* \mathbf{P}<.05$

It can be observed from Table 2 that the difference between subcategories of 'Elicitation Questions' in English texts was highly significant.

Table 3: Different Types of 'Elicitation Questions' in Persian Texts

\begin{tabular}{cccccc}
\hline $\begin{array}{c}\text { Types of Questions } \\
\text { Language }\end{array}$ & Inform & Clarity & Repeat & Agree & Commit \\
\hline $\begin{array}{c}\text { Persian } \\
\mathbf{X}^{\mathbf{2}} \mathbf{4 5 6 . 7 *}\end{array}$ & $63.50 \%$ & $24.63 \%$ & $1.49 \%$ & $8.01 \%$ & $2.37 \%$ \\
\hline
\end{tabular}

$* \mathbf{P}<.05$

Here the result of the Chi-square revealed an extremely great significant difference between the subcategories of 'Elicitation questions' in Persian.

Table 4: Different Types of Elicitation Questions in Persian and English Texts

\begin{tabular}{cccccc}
\hline $\begin{array}{c}\text { Types of Questions } \\
\text { Language }\end{array}$ & Inform & Clarity & Repeat & Agree & Commit \\
\hline English & $60.66 \%$ & $27.42 \%$ & $5.82 \%$ & $3.88 \%$ & $2.22 \%$ \\
$\begin{array}{c}\text { Persian } \\
\mathbf{X}^{\mathbf{2}} \mathbf{1 4 . 6 2} *\end{array}$ & $63.50 \%$ & $24.63 \%$ & $1.49 \%$ & $8.01 \%$ & $2.37 \%$ \\
\hline
\end{tabular}

\section{$* \mathbf{P}<.05$}

Table 4 indicates that the difference among the subcategories of 'Elicitation Questions' in English and Persian is significant.

To sum up, the tables of the five subcategories showed that both English and Persian texts demonstrated significance in Elicit: Inform and Elicit: Clarify at $\mathrm{P}<.05$. The data reported here largely support the research questions that 
Tsui's (1995) model of 'Elicitation Question' is efficient and any question regarding its function can be classified as one of the subcategories of Elicitation in English and Persian story books. The data presented in Table 1 revealed that Elicit: Inform had the highest percentage in both English and Persian texts. This finding can be considered as an indication of the fact that different forms of questions had the same function, that is, they were frequently used to elicit a piece of missing information. This table indicated that the second highest percentage belonged to Elicit: Clarify, that is 27.42 percent of the total questions in English texts and 24.63 percent of the total questions in Persian texts. Because on the results, next to getting information, the function of most the questions was seek further clarification.

Table 1 also showed that only 1.49 percent of the total 'Elicitation Questions' were Elicit: Repeat in Persian texts; while, this type of 'Elicitation Question' constituted 5.82 percent of the whole questions in English texts (i.e., the third highest percentage). In the use of Elicit: Agree, the instances of Persian texts (i.e. $8.01 \%$ of the total elicitations) were nearly twice more than that of the English ones (i.e. 3.88\%). In this table, with a total of 8 English instances of Commitment compared with 8 Persian instances of Commitment indicated that both English and Persian texts used Elicit: Commit equally. It might be the case because of the fact that the interlocutors possibly performed this function in the requestive forms.

Therefore, the highest and the lowest percentages of 'Elicitation Questions' in English texts belonged to Elicit: Inform and Elicit: Commit and in Persian texts belonged to Elicit: Inform and Elicit: Repeat respectively. The application of Chi-square test demonstrated that there were significant differences between the frequencies of the subclasses of Elicitation questions in each language and also among the frequencies of the subclasses in the two languages.

\section{Conclusion and Recommendations for Further Research}

Based on the findings and analyses of the data gathered in this research, the following conclusions are drawn:

1) It is evident that Tsui's characterization of the utterance which occurs in the initiating move and elicits an obligatory verbal response as an 'Elicitation Questions' regardless of its syntactic form is applicable to the conversational structure of English and Persian story books.

2) It appears that Tsui's classification of 'Elicitation questions' into five subcategories which is on the basis of the discourse function of the utterances is proper and workable in English and Persian story books.

3) The results of this investigation show that there are some similarities and differences in using subcategories of 'Elicitation Questions' in both English and Persian texts. That is, most of the questions in both English and Persian texts were asked for Repetition and then Agreement, while in Persian texts these tendencies were reverse. Moreover, asking for Commitment and Repetition were the least frequent types of 'Elicitation Questions' in English and Persian respectively.

4) The elicited responses are also in accordance with Tsui's classification of responding moves with reference to the third element of conversation; in most cases no follow-up move was realized. The absence of follow-up act may be accounted for by the facts that: 1) the interlocutors knew each other well, 2) those who asked a question were in a higher position in which the follow-up act might be realized non-verbally, and 3) the utterances are taken from written texts, therefore, non-verbal follow-up acts were not used.

It is recommended that further research needs to be conducted due to the limited number of studies in this field. This study focused on written text; however, future researchers can collect data from naturally occurring conversation in different settings. They can also take other influential variables such as age, gender, and nationality into consideration.

\section{References}

Coulthard, M. (1992). Advances in spoken discourse analysis. London: Routledge.

Falk, J. S. (1978). Linguistics and language: A survey of basic concepts and implications (2 ${ }^{\text {nd }}$ ed.). New York: John Wiley and Sons.

Glaspell, S. (1948). Trifles. New York: Random House.

Huddleston, R., \& Pullum, K. (2002). The Cambridge grammar of the English language. Cambridge: Cambridge University Press. 
Katz, J. J., \& Postal, P. M. (1964). An integrated theory of linguistic descriptions. Cambridge, Mass: MIT Press.

Lyons, H. (1981). Language and linguistics. Cambridge: Cambridge University Press.

Makhmalbaf, M. (1987). Arusiye-khubaan. Tehran: Sourush Publication.

Quirk, R., Greenbaum, S., Leech, G., \& Svartivk, J. (1985). A comprehensive grammar of the English language. London: Longman.

Radi, A. (1961). Rouzane-ye-Aabi. Tehran: Nikpu Publication.

Saedi, Gh. (1977). Vaay Bar Maqlub. Tehran: Aagaah Publication.

Saroyan, W. (1939). The time of your life. New York: Random House.

Sinclair, J. M., \& Coulthard, M. (1975). Towards an analysis of discourse. London: Oxford University Press.

Tsui, A. B. M. (1991). Sequencing rules and coherence in discourse. Journal of Pragmatics, 15(2), 29-111. http://dx.doi.org/10.1016/0378-2166(91)90056-4

Tsui, A. B. M. (1995). English conversation. Oxford: Oxford University Press.

William, T. (1944). The glass menagerie. New York: Random House. 